\title{
Acceleration of wound healing activity by Polygonatum odoratum leaf extract in rats
}

\author{
Fathi Farag Mughrabi ${ }^{1 *}$, Harita Hashim ${ }^{1}$, Mahmood A. A. ${ }^{2}$, Suzy S. M. ${ }^{2}$, Salmah I. ${ }^{2}$, Zahra A. A. ${ }^{2}$ \\ and Kamal K. ${ }^{3}$
}

${ }^{1}$ Department of Biology, Faculty of Applied Science University Teknologi MARA, 40450, Shah Alam, Malaysia. ${ }^{2}$ Department of Molecular Medicine, Faculty of Medicine, University of Malaya, 50603, Kuala Lumpur, Malaysia.

${ }^{3}$ Department of Chemistry, Faculty of Science, University of Malaya, 50603 Kuala Lumpur, Malaysia.

Received 9 August, 2010; Accepted 13 April, 2011

\begin{abstract}
Polygonatum odoratum is an important herbal medicine that is used in folk medicine for the treatment of various elements and its components are reported to have various biological effects. This study was conducted to evaluate the effects of topical application of ethanol leaf extract of this plant on the rate of wound healing closure and histology of healed wound. Four groups of male Sprague Dawley rats, all were experimentally wound in the posterior neck area. The animal groups were topically treated respectively with $0.4 \mathrm{ml}$ of each vehicle (gum acacia), Intrasite gel, 100 and $200 \mathrm{mg} / \mathrm{ml}$ of ethanol leaf extract. Macroscopically, wound dressed with leaf extracts and Intrasite gel-treated group significantly healed earlier than those treated with vehicle, and the rate of wound healing was significantly accelerated by topical application of $200 \mathrm{mg} / \mathrm{kg}$ leaf extract. Histological analysis of healed wounds dresses with leaf extracts showed comparatively less scar width at wound closure and healed wound contained less inflammatory cells and more collagen with angiogenesis as compared to wounds dressed with vehicle. In conclusion, wounds dressed with leaf extracts significantly enhanced the acceleration of wound healing enclosure in rats.
\end{abstract}

Key words: Polygonatum odoratum leaf, ethanol extract, wound healing, histology.

\section{INTRODUCTION}

Normal wound healing response begins the moment the tissue is injured. Wound healing is the process of repair that follows injury to the skin and other soft tissues (Nguyen et al., 2009). Proper healing of wounds is essential for the restoration of disrupted anatomical continuity and disturbed functional status of the skin (Begum and Nath, 2000). Healing is a complex and intricate process initiated in response to an injury that restores the function and integrity of damaged tissues (Govindarajan et al., 2007). Wound healing involves continuous cell-cell and cell-matrix interactions that allow the process to proceed in three overlapping phases, inflammation, cellular proliferation and remodeling (Martin, 1996; Souba and Wilmore, 1999). It is accepted that wound repair is an immune-mediated physiologic mechanism (Singer and Clark, 1999). Several plants and herbs have been used experimentally to treat skin disorders, including wound injuries, in traditional medicine (Karodi et al., 2009; Csupor et al., 2010).

Polygonatum odoratum (Liliaceae) is a perennial plant 
that grows in the wild and is cultivated in the Southeastern Asian countries such as Indonesia, Malaysia, and Thailand. It is an important herbal medicine that is used in folk medicine for the treatment of respiratory diseases in oriental medicine and its components were reported to have various biological effects (Lee et al., 2004). $P$. odoratum methanolic leaf extract exhibited strong antioxidant and antibacterial activities and moderately inhibitory effect on breast cancer cell (MCF-7) proliferation (Nasasombat and Teckchuen, 2009). Flavonoids found in the leaf of this plant were rutin, catechin, quercetin, kaempferol and isorhamnetin, which are responsible for its various biological and pharmacological properties. Among these compounds, rutin was found in the highest amount (Nasasombat and Teckchuen, 2009). The kaempferol derived from $P$. odoratum has been used for the treatment of chronic airway diseases (Lee et al., 2004). P. odoratum had high phenolic content and antioxidant activity (Nasasombat and Teckchuen, 2009). Phenolic compounds, such as flavonids, tannins and phenolic acid, are plant metabolites widely spread throughout the plant kingdom. They have diverse biological functions such as anti-inflammatory, anticarcinogenic and cardiovascular protective effects. These functions might be associated with their antioxidative activity (Li et al., 2007). Several studies have shown that rhizomes of this plant may contain pharmacologically active compounds. Homoisoflavanones from $P$. odoratum rhizomes inhibit advanced glycation end product formation (Dong et al., 2010). P. odoratum showed the potent intestinal immune system modulating activity (Hwang et al., 2008), exhibited ability to induce osteoclast differentiation (Youn et al., 2008) and P. odoratum lectin induces apoptosis, as well as amplifies TNFa-induced L929 cell apoptosis (Liu et al., 2009), and may serve as a kind of immunopotentiator for mammals (Xiao et al., 1990). There were no data regarding the wound healing effect of $P$. odoratum leaf extract, and to confirm their traditional uses as a remedy for wound healing. This encourages us to assess the rate of wound healing enclosure of $P$. odoratum leaf extract macroscopically and microscopically in rats.

\section{MATERIALS AND METHODS}

\section{Intrasite gel}

Intrasite gel was purchased from University Malaya Medical Center Pharmacy. Intrasite gel is an amorphous hydrogel which gently rehydrates necrotic tissue, and facilitate autolytic debridemen, while being able to loosen and absorb slough and exudates, cleaning the way for effective wound healing. Therefore, $0.2 \mathrm{ml}$ of Intrasite gel was applied topically twice daily to the wound of group 2 rats (Intrasite gel is a trademark for Smith and Nephew Ltd) (Williams, 1994).

\section{Lignocaine $\mathrm{HCl}(2 \%, 100 \mathrm{mg} / 5 \mathrm{ml})$}

Lignocaine is a local anesthesia and was purchased from the
Experimental Animal House, Faculty of Medicine, University of Malaya. One liter of lignocaine was injected subcutaneously.

\section{$P$. odoratum leaves extract preparation}

Fresh leaves of $P$. odoratum were obtained from Ethno Resources Sdn Bhd, Selangor Malaysia, and identified by comparison with the voucher specimen deposited at the Herbarium of Rimba IImu, Institute of Science Biology, University of Malaya, Kuala Lumpur. The leaf was tap washed followed by washing with distilled water. The leaf was shade-dried for 7 to 10 days and was then finely powdered using electrical blender. $100 \mathrm{~g}$ of fine powder was soaked in $1000 \mathrm{ml}$ of $95 \%$ ethanol in conical flask for 3 days in room temperature. After the mixture was filtered using a fine muslin cloth followed by filter paper (Whatman No. 1) and distilled under reduced pressure in an Eyela rotary evaporator (Sigma-Aldrich, USA). The extract was placed in incubator to dry at $40^{\circ} \mathrm{C}$ for two days and the solid extract was dissolved by using the vehicle, gum acacia in normal saline as described by Shetty et al. (2007). Two grams of gum acacia was dissolved in $100 \mathrm{ml}$ of normal saline. From this, $10 \mathrm{ml}$ of solution, which contains $200 \mathrm{mg}$ of gum acacia, was used for dissolving 1 and $2 \mathrm{~g}$ of ethanol extract each. So $1 \mathrm{ml}$ of each solution contains 100 and $200 \mathrm{mg}$ of extract, respectively $(100 \mathrm{mg} / \mathrm{ml}=40 \mathrm{mg} / 0.4 \mathrm{ml}$ and $200 \mathrm{mg} / \mathrm{ml}=80 \mathrm{mg} / 0.4 \mathrm{ml}$ ).

\section{Acute toxicity studies}

The acute toxic study was used to determine a safe dose for $P$. odoratum. Thirty six healthy Sprague Dawley rats (18 males and 18 females) were obtained from the Experimental Animal House, Faculty of Medicine, University of Malaya, and were assigned equally into 3 groups labeled as vehicle (gum acacia in normal saline); 2 and $5 \mathrm{~g} / \mathrm{kg}$ of $P$. odoratum in vehicle, respectively. The animals were fasted overnight (food but not water) prior dosing. Food was withheld for a further 3 to $4 \mathrm{~h}$ after dosing. The animals were observed for $30 \mathrm{~min}$ and 2, 4, 24 and $48 \mathrm{~h}$ after the administration for the onset of clinical or toxicological symptoms. Mortality, if any was observed over a period of 2 weeks. The animals were sacrificed on the 15th day. Serum biochemical and histological (liver and kidney) parameters were determined following standard methods (Abdullah et al., 2009; Chandrasekaran et al., 2009). The study was approved by the ethics committee for animal experimentation, Faculty of Medicine, University of Malaya, Malaysia with Ethic No. PM/07/05/2009/MMA (a) (R). Throughout the experiments, all animals received human care according to the criteria outlined in the "Guide for the Care and Use of Laboratory Animals" prepared by the National Academy of Sciences and published by the National Institute of Health.

\section{Wound healing activity of Polygonatum odoratum}

\section{Experimental animals}

Sprague Dawley healthy adult male rats were obtained from the Experimental Animal House, Faculty of Medicine, University of Malaya, and the rats were divided randomly into 4 groups of 8 rats each. Each rat that weighted between 220 and $250 \mathrm{~g}$ (8 to 9 weeks old) was housed separately (one rat per cage). The rats were maintained on standard pellet diet and tap water. The study was approved by the ethics committee for animal experimentation, Faculty of Medicine, University of Malaya, Ethic No. PM/27/07/2009/MAA (R). Throughout the experiments, all animals received human care according to the criteria outlined in the "Guide for the Care and Use of Laboratory Animals" prepared by the National Academy of Sciences and published by the National 
Table 1. Time required for wound healing by $P$. odoratum leaf extract in rats.

\begin{tabular}{cclc}
\hline Group & $\begin{array}{c}\text { No. of } \\
\text { animals }\end{array}$ & $\begin{array}{l}\text { Type of dressings (twice daily) } \\
(\mathbf{0 . 4} \mathbf{~ m l} / \text { wound) }\end{array}$ & $\begin{array}{c}\text { Healing time (days) } \\
\text { (Mean } \pm \text { SEM) }\end{array}$ \\
\hline 1 & 8 & Gum acacia $(20 \mathrm{mg} / \mathrm{ml})$ & $21.50 \pm 0.76^{\mathrm{a}}$ \\
2 & 8 & Intrasite gel $($ standard control) & $14.17 \pm 0.48^{\mathrm{b}}$ \\
3 & 8 & P. odoratum $(100 \mathrm{mg} / \mathrm{ml})$ & $16.67 \pm 0.42^{\mathrm{c}}$ \\
4 & 8 & P. odoratum $(200 \mathrm{mg} / \mathrm{ml})$ & $14.33 \pm 0.33^{\mathrm{b}}$ \\
\hline
\end{tabular}

All values were expressed as mean and \pm standard error mean. Mean with different superscripts were significantly different $(P<0.05)$.

Institute of Health.

\section{Experimentally induced excision wounds}

The animals were anesthetized with diethyl ether prior to creation of the wounds. The skin shaved by electrical clipper, disinfected with $70 \%$ alcohol and injected with $1 \mathrm{ml}$ of lignocaine $\mathrm{HCl}(2 \%, 100 \mathrm{mg} / 5$ $\mathrm{ml}$ ). An area of uniform wound $2.00 \mathrm{~cm}$ in diameter (circular area $=$ $3.14 \mathrm{~cm}^{2}$ ), using circular stamp, was excised from the nape of the dorsal neck of all rats with the aid of round seal as described by Morton and Melone (1972) with slight modification. Avoid incision of the muscle layer and tension of skin was kept constant during the procedure. The entire wound was left open in the work of Nayak et al. (2005). The wound area was measured immediately under light diethyl ether anesthesia by placing a transparent tracing paper over the wound and tracing it out. The tracing paper was placed on 1 $\mathrm{mm}^{2}$ graph sheet, and traced out. The squares were counted and the area recorded, as described by Chah et al. (2006).

\section{Topical wound application}

Wounds of group 1 animals were topically treated with $0.4 \mathrm{ml}$ of vehicle, gum acacia in normal saline $(20 \mathrm{mg} / \mathrm{ml})$, twice daily as placebo control group (Shetty et al., 2007). Wounds of group 2 rats were topically treated with $0.4 \mathrm{ml}$ of Intrasite gel twice daily as a reference standard control. Moreover, $0.4 \mathrm{ml}$ of 100 and $200 \mathrm{mg} / \mathrm{ml}$ of ethanol extract of $P$. odoratum in vehicle each were applied topically twice daily to the wound of groups 3 and 4, respectively. The wound was observed daily until complete wound-healing enclosure occurs.

\section{Estimation of wound healing (wound closure)}

Wound areas were traced manually and calculated in square millimeters. The wound closure area of each animal was assessed by tracing the wound on days $0,5,10$, and 15 post-wounding surgery and the wound closure rate was expressed as the percentage of wound area compared with that on post-operative day by using transparency paper and a permanent marker under light diethyl ether anesthesia as described by Nayak and PintoPereira (2006). The wound areas recorded were measured using a graph paper. The percent wounds healing on these days are determined (Chah et al., 2006). Number of days required for falling of scar without any residual raw wound gave the period of epithelization.

\section{Histological evaluation of healed wounds}

The skin specimen from wounds healed areas were fixed in $10 \%$ buffered formalin and processed by paraffin tissue processing machine. The healed skin was assessed by taking a 5 microsection, stained with hematoxylin and eosin.

\section{Statistical analysis}

All values are reported as mean \pm standard error of mean (SEM) and the statistical significance of differences among groups were assessed using one-way analysis of variance (ANOVA). A value of $p<0.05$ was considered significant.

\section{RESULTS}

\section{Acute toxicity}

Acute toxicity study is a study in which the animals were treated with the $P$. odoratum leaf extract at a dose of 2 and $5 \mathrm{~g} / \mathrm{kg}$ were kept under observation for 14 days. All the animals remained alive and did not manifest any significant visible of toxicity at these doses. Thus, clinical observations, blood biochemistry and histopathology data did not show any significant differences between control and treated groups. It was concluded that $P$. odoratum was orally administered to rats safe and that no drugrelated toxicity was detected even at the highest dose investigated.

\section{Wound healing activity}

Wounds dressed with of $P$. odoratum-treated groups or reference standard control wounds showed considerable signs of dermal healing and significantly healed faster as compared with those who received the placebo control treatment (gum acacia in normal saline) (Table 1). Table 2 showed the effects of $P$. odoratum on the percentage of wound healed on days post surgery. Throughout the experiment, the percentage healing in placebo control group wounds was significantly lower than those of $P$. odoratum-treated groups and reference standard control wounds. Histologically, $P$. odoratum-treated groups contained comparatively less scar at wound closure than the placebo-treated group (Figure 1a and b), and the granulation tissue in healed wound contained comparatively few inflammatory cells, and more collagen 
Table 2. Effect of $P$. odoratum on percentage (\%) of wound healing in experimental rats.

\begin{tabular}{llccc}
\hline \multirow{2}{*}{ Group } & \multirow{2}{*}{ Treatment (twice daily, 0.4 ml) } & \multicolumn{2}{c}{ Percentage wound healing (Mean \pm S.E.M) on day post surgery } \\
\cline { 3 - 5 } & & $\mathbf{5}$ days & $\mathbf{1 0}$ days & $\mathbf{1 5}$ days \\
\hline $1(\mathrm{n}=8)$ & Gum acacia in normal saline & $35.17 \pm 0.65^{\mathrm{a}}$ & $72.33 \pm 0.84^{\mathrm{a}}$ & $87.83 \pm 2.57^{\mathrm{a}}$ \\
$2(\mathrm{n}=8)$ & Intrasite gel & $75.33 \pm 0.76^{\mathrm{b}}$ & $94.00 \pm 0.86^{\mathrm{b}}$ & $1000 \pm 0.0^{\mathrm{b}}$ \\
$3(\mathrm{n}=8)$ & $P$. odoratum $(100 \mathrm{mg} / \mathrm{ml})$ & $65.00 \pm 0.73^{\mathrm{c}}$ & $88.67 \pm 1,02^{\mathrm{c}}$ & $100.0 \pm 0.0^{\mathrm{b}}$ \\
$4(\mathrm{n}=8)$ & P. odoratum $(200 \mathrm{mg} / \mathrm{ml})$ & $74.00 \pm 0.86^{\mathrm{b}}$ & $95.50 \pm 0.76^{\mathrm{b}}$ & $1000 \pm 0.0^{\mathrm{b}}$ \\
\hline
\end{tabular}

All values were expressed as mean and \pm standard error mean. Mean with different superscripts were significantly different $(P<0.05)$.
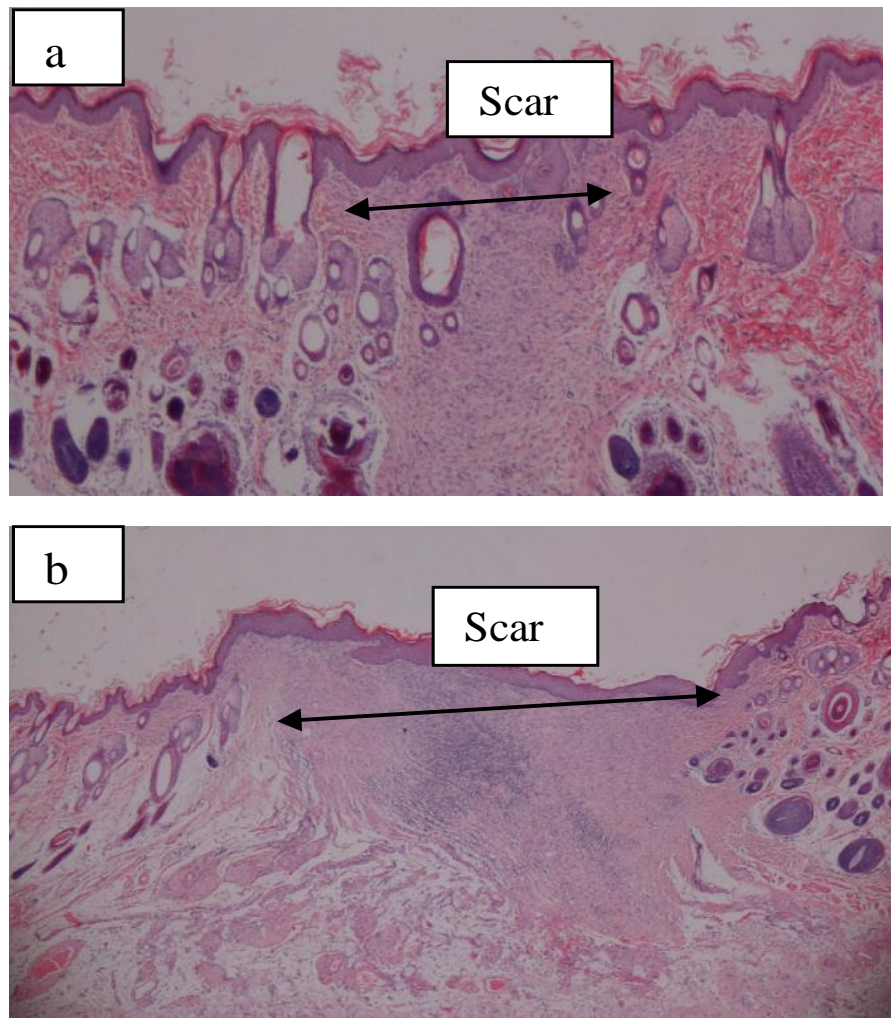

Figure 1. Histological section of healed wound in (a) $200 \mathrm{mg} / \mathrm{kg}$ of $P$. odoratum-treated group showing narrow scar region of wound closure, (b) gum acacia-treated group showing wide scar region of wound enclosure (H \& E stain $4 x)$.

and proliferating blood capillaries (angiogenesis) compared with placebo-treated group (Figure $2 a$ and b).

\section{DISCUSSION}

Wound healing is a complex and dynamic process of restoring cellular structures and tissue layers in damaged tissue as closely as possible to its normal state. Wound contracture is a process that occurs throughout the healing process, commencing in the fibroblastic stage whereby the area of the wound undergoes shrinkage. In the maturational phase, the final phase of wound healing the wound undergoes contraction resulting in a smaller
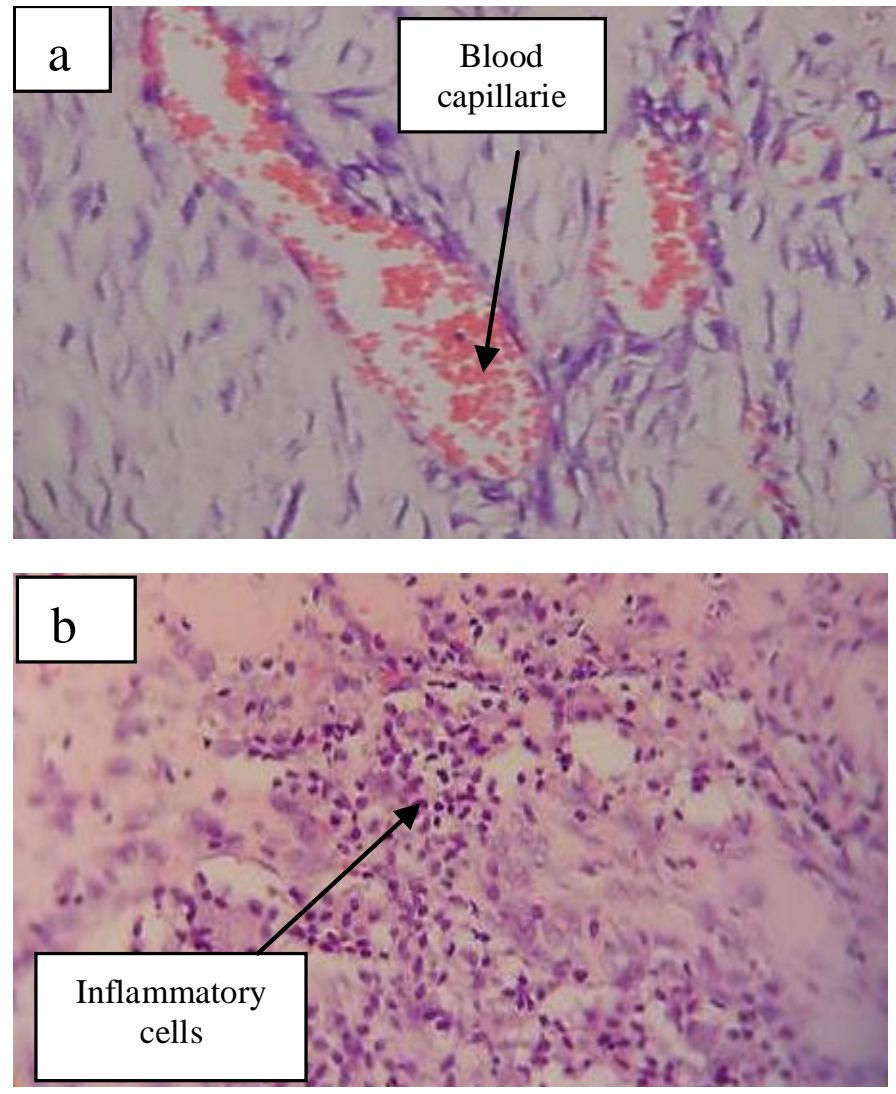

Figure 2. Histological section of healed wound in (a) $200 \mathrm{mg} / \mathrm{kg}$ of $P$. odoratum-treated group. Granulation tissue contains comparatively more collagen, fibroblast and blood capillaries, and few inflammatory cells. (b) Gum acacia-treated group. Granulation tissue contains comparatively less collagen, fibroblast and blood capillaries, and more inflammatory cells ( $\mathrm{H} \& \mathrm{E}$ stain $40 \mathrm{x}$ ).

amount of apparent scar tissue (Midwood et al., 2004). In the current study, topical application of $P$. odoratum significantly accelerated the rate of wound healing, and histology, healed wound contain comparatively less inflammatory, more collagen and angiogenesis. Wound healing effects may be due to increase in collagen (Bonte et al., 1993) and increase in tensile strength of the wounds (Suguna et al., 1996). Simillarly, enhanced healing activity has been attributed to increased collagen formation and angiogenesis (Trabucchi et al., 1986; 
Shukla et al., 1999). Collagen played a central role in the healing of wounds and it is a principal component of connective tissue and provides a structural framework for the regenerating tissue (Cohen et al., 1992). Angiogenesis in granulation tissues improves circulation to the wound site, thus providing oxygen and nutrients essential for the healing process (Szabo et al., 1995) that includere-epithelization. Stimulate epithelial cell proliferation and angiogenesis are important for wound healing process (Buntrock et al., 1982). Habibipour et al. (2003) showed that histological analysis of the treated healed wound group contained a large amount of fibroblast proliferation, collagen synthesis, and neovascularization, which resulted in an increased wound tensile strength and accelerated healing wound.

$P$. odoratum leaf extract possessed strong antioxidant, antibacterial, and anti-breast cancer activity (Nasasombat and Teckchuen, 2009). Flavonoids found in the leaf of this plant may be responsible for wound-healing activity, and studies with plant extracts have shown that constituent like flavonoids (Tsuchiya et al., 1996) are known to promote the wound-healing process mainly due to their antimicrobial properties, which appear to be responsible for wound contraction and increased rate of epithelialization. Flavonoids can scavenge the reactive oxygen species (super-oxide anions) and free radicals produced. These reactive intermediates are potentially implicated in delayed wound healing (Lewis and Hanson, 1991). Flavonoids are known to reduce lipid peroxidation not only by preventing or slowing the onset of cell necrosis, but also by improving vascularity. The higher the flavonoids content, the stronger the antioxidant activity. Significant amounts of flavonoids existed in $P$. odoratum leaves (Nasasombat and Teckchuen, 2009), therefore, supplementing a balanced diet with its leaves may have beneficial health effects. Hence, any drug that inhibits lipid peroxidation is believed to increase the viability of collagen fibers by increasing the strength of collagen fibers, increasing the circulation, preventing the cell damage and by promoting the DNA synthesis (Getie et al., 2002).

Mechanisms of wound healing may be contributed to stimulate the production of antioxidants in wound site and provides a favorable environment for tissue healing (Shukla et al., 1999). P. odoratum has shown antioxidant activity (Nasasombat and Teckchuen, 2009). It have been reported that antioxidants may play a significant role in the wound healing process and may be important contributory factor in the wound healing property (Shukla et al., 1999). Antioxidants have been reported to play a significant role in the wound healing process and significantly improve wound healing and protect tissues from oxidative damage (Martin, 1996).

In conclusion, $P$. odoratum extract showed remarkable wound healing activity and it may be suggested for treating various types of wounds in human being. The acute toxicity profile of $P$. odoratum leaf extract could be considered favorable judging from the absence of adverse clinical manifestations in experimental animals after. Further studies with purified constituents are needed to understand the complete mechanism of wound healing activity of $P$. odoratum

\section{ACKNOWLEDGEMENT}

This study was financially supported by the University of Malaya through University Malaya Research Grand 2010 (UMRG), RG102/09HTM.

\section{Conflict of Interests}

The author(s) have not declared any conflict of interests.

\section{REFERENCES}

Abdullah NR, Ismail Z, Ismail Z (2990). Acute toxicityof Orthosiphon stamineus Benth standardizedextractin Sprague Dawleyrats. Phytomedicine16:222-226.

Begum D, Nath SC (2000). Ethnobotanical review of medicinal plants used for skin diseases and related problems in Northeastern India. J. Herbs Spices Med. Plants 7:55-93.

Bonte F, Dumas M, Chadgne, Meybeck A (1993). Influence of asiatic acid, madecassic acid, and asiaticoside on human collagen I synthesis. Planta Med. 60:133-135.

Buntrock P, Jentzsch KD, Heder G (1982). Stimulation of wound healing. Using brain extract with fibroblast growth factor (FGF) activity. II. Histological and morphometric examination of cells and capillaries. Exp. Path. 21:62-67.

Chah KF, Eze CA, Emuelosi CE, Esimone CO (2006). Antibacterial and wound healing properties of methanolic extracts of some Nigerian medicinal plants. J. Ethnopharmacol. 104:164-167.

Chandrasekaran CV, Thiyagarajan P, Sundarajan K, Krishna S, Goudar M, Deepak, Murali B, Joshua Allan J, Agarwal A (2009). Evaluation of the genotoxic potential and acute oral toxicity of standardized extract of Andrographis paniculata. Food Chem.Toxicol. 47:1892-1902.

Csupor D, Blazso G, Balogh A, Hohmann J (2010). The traditional Hungarian medicinal plant Centaurea sadleriana Janka accelerates wound healing in rats. J. Ethnopharmacol. 127:193-195.

Dong W, Shi HB, Ma H, Miao YB, Liu TJ, Wang W (2010). Homoisoflavanones from Polygonatum odoratum Rhizomes Inhibit Advanced Glycation End Product Formation. Arch. Pharm. Res. 33:669-674.

Getie M, Gebre Mariam T, Reitz R, Neubert RH (2002). Evaluation of the release profiles of flavonoids from topical formulations of the crude extract of the leaves of Dodonea viscosa (Sapindaceae). Pharmazie. 57:320-322

Govindarajan RA, Pushpangadan P, Kumara B, Vijayakumar M (2007). Ethnopharmacological approaches to wound healing-Exploring medicinal plants of India. J. Ethnopharmacol. 114:103-113.

Habibipour S, Oswald TM, Zhang F, Joshi P, Zhou XC, Dorsett-Martin W, Lineaweaver WC (2003). Effect of sodium diphenylhydantion on skin wound healing in rats. Plast Reconstr. Surg. 112:1620-1627.

Hwang JH, Suh HJ, Yu KW (2008). Immunostimulating and Anticancer Activities of Hot-water Extracts from Acanthopanax senticosus and Glycyrrhiza uralensis. Food Sci. Biotechnol. 17:1185-1190.

Karodi R, Jadhav M, Rub R, Bafna A (2009). Evaluation of the wound healing activity of a crude extract of Rubia cordifolia L. (Indian madder) in mice. Int. J. Appl. Res. Natural Prod. 2:12-18.

Lee CJ, Lee JH, Seok JH, Hur GM, Park Js J, Bae S, Lim JH, Park YC (2004). Effects of betaine, coumarin and flavonoids on mucin release from cultured hamster tracheal surface epithelial cells. Phytother. Res. 18:301-305. 
Lewis DA, Hanson PJ (1991). Antiulcer drugs of plant origin. Prog. Med. Chem. 28:210-229.

Li WY, Chan SW, Guo DJ, Yu PHF (2007). Correlation between antioxidative power and anticancer activity in herbs from traditional Chinese medicine formulae with anticancer therapeutic effect. Pharmaceut. Biol. 45:541-546.

Liu B, Zhang B, Min MW, Bian HJ, Chen LF, Liu Q, Bao JK (2009). Induction of apoptosis by Polygonatum odoratum lectin and its molecular mechanisms in murine fibrosarcoma L929 cells. Biochimica et Biophysica Acta. 1790: 840-844

Martin A (1996). The use of antioxidants in wound healing. Dermatol. Surg. 22:156-160.

Midwood KS, Williams LV, Schwarzbauer JE (2004). Tissue repair and the dynamics of the extracellular matrix. Int.I J. Biochem. Cell Biol. 36:1031-1037.

Morton JJ, Molane MH (1972). Evaluation of vulnerary activity by an open wound procedure in rats. Arch. Int. Pharmacodyn. Ther. 196: 117-126.

Nasasombat S, Teckchuen N (2009). Antimicrobial, antioxidant and anticancer activities of Thai local vegetables. J. Med. Plants Res. 3:443-449.

Nayak BS, Pinto-Pereira LM (2006). Catharanthus roseus flower extract has wound-healing activity in Sprague Dawley rats. BMC Complementary Altern. Med. 6:41-47.

Nayak BS, Vinutha B, Geetha B, Sudha B (2005). Experimental evaluation of Pentas lanceolata for wound healing activity in rats. Fitotherapia. 76: 671-675.

Nguyen DT, Orgill DP, Murphy GF (2009). Chapter 4: The pathophysiologic basis for wound healing and cutaneous regeneration. Biomaterials For Treating Skin Loss. CRC Press (US) \& Woodhead Publishing (UK), Boca Raton/Cambridge pp. 25-57.

Shetty S, Udupa S,Udupa L (2007). Evaluation of antioxidant and wound healing effects of alcoholic and aqueous extract of Ocimum sanctum in rats. Evidence-based Cpmplementary and Alternative medicine. 51:95-101.

Shukla A, Rasik AM, Dhawan BN (1999). Asiaticoside-induced elevation of antioxidant levels in healing wounds. Phytother. Res. 13:50-54.

Singer AJ, Clark RA (1999). Cutaneous wound healing. N. Engl. J. Med. 341:738-746.

Souba WW, Wilmore D (1999). Diet and nutrition in case of the patient with surgery, Trauma and sepsis. In: Shils M, Olson J, Shike M, Ross AC, editor. Modern Nutrition in Health and Disease. 9. Baltimore, Williams and Wilkins pp. 1589-1618.
Suguna L, Sivakumar P, Chandrakasan G (1996). Effects of Centella asiatica extract on dermal wound healing in rats. Ind. J. Exp. Biol. 34:1208-1211.

Szabo S, Kusstatscher S, Sakoulas G, Sandor Z, Vincze A, Jadus M (1995). Growth factors: New "endogeneous drug" for ulcer healing. Scandinavian J. Gastroenterol. pp. 15-18.

Trabucchi E, Preis-Baruffaldi F, Baratti C, Montorsi W (1986). Topical treatment of experimental skin lesions in rats: macroscopic, microscopic and scanning electron-microscopic evaluation of the healing process. Int. J. Tissue React 8:533-544.

Tsuchiya H, Sato M, Miyazaki T, Fujiwara S, Tanigaki S, Ohyama M, Tanaka T (1996). linuma M: Comparative study on the antibacterial activity of phytochemical flavanones against methicillin-resistant Staphylococcus aureus. J. Ethnopharmacol. 50:27-34

Williams C (1994). Intrasite Gel: a hydrogel dressing. Br. J. Nurs. 3:843846.

Xiao J, Cui F, Ning T, Zhao W (1990). Effects of alcohol extract from Polygonatum odoratum (Mill.) Druce and Cuscuta australis R. Br. on immunological function of mice injured by burns. Zhongguo Zhong Yao Za Zhi. 5: 557-579.

Youn YN, Lim E, Lee N, Kim YS, Koo MS, Choi SY (2008). Screening of Korean medicinal plants for possible osteoclastogenesis effects in vitro. Genes Nutr. 2:375-380. 